\title{
ANALISIS TEKSTUR PADA CITRA IRIS MATA MENGGUNAKAN ALGORITMA GRAY LEVEL CO-OCCURENCY MATRIX
}

\author{
Asti Herliana'; Toni Arifin² \\ Teknik Informatika \\ Universitas BSI Bandung \\ astiherliana79@gmail.com \\ toni.tfn19@gmail.com
}

\begin{abstract}
According to data from the ministry of health, with the high intensity of use the gadget nowadays, therefore the number of people with eye disease is increasing. To overcome increase suffers of eye disease, it takes need early detection for who suffers potentially eye disease so that handling and prevention of blindness from eye disease effect can be immediately. The process detection of eye disease can be see in iris, there are several disease can be seen in iris among there are diabetic retinopathy and glaucoma. This research present texture analysis for iris images, the method is used GLCM (Gray Level Co-occurency Matrix) which is implemented using Matlab, and using 5 parameters namely contrast, correlation, energy, homogeneity and entropy. Process analysis texture is developed with preprocessing technique, the result of texture in images data iris can be recognized and produce the dataset of result from feature extraction with GLCM (Gray Level Co-occurency Matrix).
\end{abstract}

Keywords: Iris, Texture Analysis, Gray Level Cooccurrence Matrix.

Intisari- Menurut data dari kementrian kesehatan, dengan intensitas penggunaan gadget yang cukup tinggi dewasa ini, maka jumlah penderita penyakit mata semakin meningkat. Untuk menanggulangi peningkatan penderita penyakit mata, maka dibutuhkan suatu pendeteksian sejak dini untuk para penderita yang berpotensi terkena penyakit mata sehingga penanganan dan pencegahan terhadap kebutaan akibat penyakit mata dapat segera dilakukan. Proses pendeteksian penyakit mata ini bisa dilihat dari iris mata, ada beberapa penyakit yang bisa diamati lewat iris mata diantaranya diabetes retinopathy dan glaukoma. Penelitian ini menyajikan analisa tekstur untuk citra iris mata, metode yang digunakan adalah GLCM (Gray Level Co-occurency Matrix) yang diimplementasikan menggunakan Matlab, dan menggunakan 5 parameter yaitu contrast, correlation, energy, homogeneity dan entropy. Proses analisa tekstur dikembangkan dengan menggunakan teknik preprocessing, hasilnya tekstur pada data citra iris mata dapat dikenali dan menghasilkan dataset hasil dari feature extraction menggunakan GLCM (Gray Level Co-occurency Matrix).

Kata Kunci: Iris mata, Analisa Tekstur, Gray Level Co-occurency Matrix.

\section{PENDAHULUAN}

Gangguan penglihatan dan kebutaan saat ini masih menjadi masalah kesehatan di Indonesia. Survey Kesehatan menunjukkan 1,5\% dari jumlah penduduk Indonesia mengalami kebutaan disebabkan oleh katarak 52\%, glaukoma 13,4\%, kelainan refraksi 9,5\%, gangguan retina $8,5 \%$, kelainan kornea $8,4 \%$ dan penyakit mata lain (Pusat Komunikasi Publik Sekretariat Jenderal Kementerian Kesehatan RI, 2010).

Data yang dilansir oleh Kementrian Kesehatan Republik Indonesia ini dimungkinkan karena sifat dari penyakit mata seperti glaucoma dan diabetes retinopathy yang menyerang secara perlahan (progresif) namun pasti, sehingga seringkali para penderitanya tidak menyadari telah terkena penyakit ini sampai penyakit ini telah mencapai tahap yang sulit disembuhkan (Herliana, Arifin, Susanti, \& Hikmah, 2018). Begitu berbahayanya penyakit ini, karena sifat dari kebutaan yang dihasilkan dari penyakit ini bersifat permanen (Arifin \& Herliana, 2018). Meski penyakit ini berbahaya, namun hingga saat ini, penyakit glaukoma masih belum ditemukan obatnya secara khusus, selama ini pengobatan terhadap penderita penyakit seperti glaucoma dan diabetes retinopathy masih bersifat mengontrol dan mencegah penyakit ini untuk berkembang ke tahap yang lebih parah (Bron, \& James, 2005).

Untuk mengetahui keberadaan penyakit ini dalam mata seorang pasien hingga saat ini masih dibutuhkan proses skrining yang rutin terutama pada pasien yang memiliki riwayat keluarga yang mengalami penyakit glaukoma. Untuk proses skrining sendiri, tentunya harus dilakukan berdasarkan kesadaran dari pasien yang memang masih minim. Minimnya kesadaran pasien untuk melakukan pemeriksaan mata ini juga mungkin 
disebabkan karena, pasien yang telah mengalamai tahap awal penyakit tidak menyadari adanya kerusakan karena dirasakan tidak ada hal yang dirasakan mengganggu sistem penglihatannya (Biro Komunikasi dan Pelayanan Masyarakat, 2018).

Teknologi informasi sangat diperlukan untuk mempercepat proses identifikasi sejak dini keberadaan penyakit mata pada seorang pasien, dengan memanfaatkan hasil ekstraksi ciri gray level co-occurrence matrix (GLCM) (Widodo, Widodo, \& Supriyanto, 2018). Metode ekstraksi ciri gray level co-occurrence matrix (GLCM) dapat menghasilkan berbagai fitur yang bertujuan untuk mengidentifikasi dan membandingkan ukuran region dan jarak ketetanggaan (Situmorang, Widodo, \& Rahman, 2019). Metode ini menghasilkan nilai matrik dari setiap tekstur dengan menggunakan 6 parameter diantaranya Entropy, Contrast, Correlation, Energy, Homogeneity, Deviation dan Brightness dengan 4 derajat keabuan diantaranta 0 derajat, 45 derajat, 90 derajat dan 135 derajat (Arifin, Riana, \& Hapsari, 2014).

Beberapa penelitian lain dengan mengunakan objek citra iris mata telah dilakukan, diantaranya Penelitian yang dilakukan oleh Ibrahim Mesecan, Alaa Eleyan dan Bekir Karlik pada tahun 2013. Pada penelitian pertama ini dihasilkan sebuah dataset citra iris mata yang dihasilkan dari pemisahan sub segmen citra iris sekaligus membuktikan bahwa dengan menggunakan data citra yang diekstraksi dapat meningkatkan kinerja dari basis data yang dihasilkan dari penelitian ini (Mesecan, Eleyan, \& Karlik, 2013). Penelitian selanjutnya yang dijadikan acuan untuk penelitian kali ini adalah penelitian yang dilakukan oleh N.Annu dan Judith Justin pada tahun 2013 dimana pada penelitian ini dilakukan penelitian secara khusus mengenai klasifikasi penyakit glaukoma dengan pendekatan analisis fitur tekstur. Hasil dari penelitian yang dilakukan oleh Annu dan Justin ini adalah didapatkannya tingkat akurasi dalam klasifikasi sebesar 95\% dengan menggunakan metode Probabilistic Neural Network (PNN) (Annu \& Justin, 2013). Penelitian terakhir yang dijadikan acuan pada penelitian kali ini adalah penelitian yang dilakukan oleh Anantrasirichai, Alin Achim, James E Morgan, Irina Erchova dan Lindsay Nicholson pada tahun 2013. Pada penelitian ini dibuktikan bahwa dengan menggunakan fitur tekstur terhadap data citra dapat meningkatkan tingkat akurasi jika dibandingkan dengan tingkat akurasi yang hanya mengandalkan tingkat ketebalan layer (Anantrasirichai, Achim, Morgan, Erchova, \& Nicholson, 2013)
Pada peneltian ini akan difokuskan pada Analisa tekstur citra iris mata, dengan tujuan untuk mendapatkan dataset atau himpunan data yang nantinya akan digunakan sebagai basis pengetahuan dalam tahapan klasifikasi penyakit mata khususnya Glaukoma dan diabetes retinopathy.

\section{BAHAN DAN METODE}

Dalam penelitian ini ada beberapa tahapan yang akan dilalui diantaranya sebagaiberikut:

1. Tahapan pertama yaitu akuisisi citra, tahapan ini adalah tahapan pencarian sampel dan seleksi data penelitian yaitu citra iris mata.

2. Tahapan kedua adalah pengolahan data awal, pada tahap ini citra yang sudah di proses akan melewati proses konversi citra yaitu ko nversi citra RGB ke Grayscale, yang kedua perbaikan kualitas citra/peningkatan mutu citra dengan menggunakan metode CLAHE (Contrast Limited Adaptive Histogram Equalization), dan langkah selanjutnya adalah dengan menggabungkan 3 teknik yaitu Range Filtering, Bottom hat filtering, dan Top hat filtering, tujuannya adalah untuk mendapatkan bentuk tekstur yang detail dari citra iris mata.

3. Tahapan selanjutnya adalah mengeluarkan nilai tekstur dengan menggunakan metode GLCM (Gray Level Co-ocrruency Matrix).

4. Hasil dari algoritma GLCM (Gray Level Coocrruency Matrix) adalah data set yang nantinya akan digunakan dalam tahapan Analisa lebih lanjut.

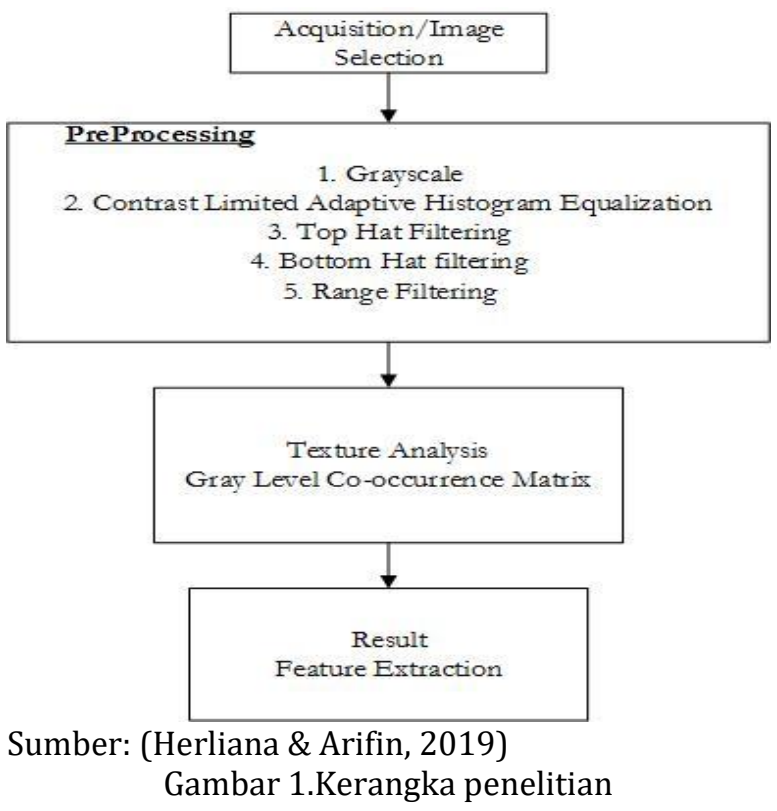


A. Akuisis Citra/Pemilihan Data

Data yang digunakan dalam penelitian kali berasal dari basis data citra iris mata Dept. Computer Science, Palacky University yang berlokasi di Olomouc, Republik Ceko. Data ini dapat diunduh melalui halaman http://phoenix.inf.upol.cz// atau https://sites.google.com/site/imesecan/databases -used (Dobe \& Machala, 2012). Data yang digunakan pada penelitian ini adalah Data normal 200 data dan data Abnormal 52 data. Berikut disampaikan contoh data citra yang digunakan dalam penelitian kali ini:

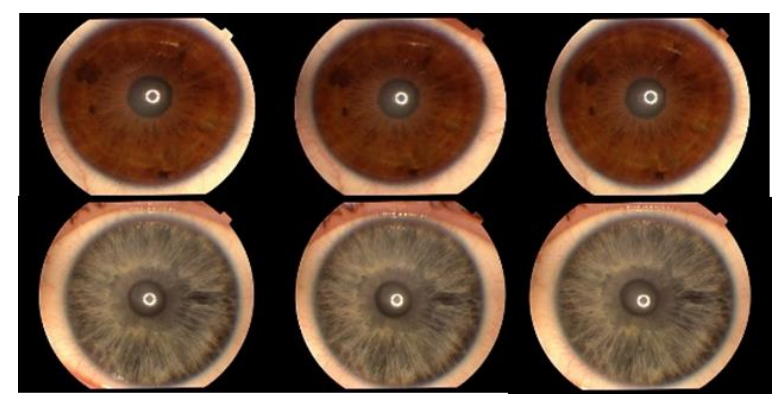

Sumber: (Herliana \& Arifin, 2019)

Gambar 2. Sampel data citra iris mata Dept. Computer Science, Palacky University

\section{B. Preprocessing}

Pada tahapan pengolahan data awal yang akan dilakukan ada 5 tahapan yaitu grayscale, CLAHE, Range Filtering, Top hat filtering dan bottom hat filtering. Dibawah ini adalah hasil dari ke 5 tahapan tersebut.

\section{Grayscale}

Pada tahap ini menggunakan fungsi rgb2gray pada matlab dengan tujuan untuk mengubah gambar RGB menjadi skala abu-abu dengan menghilangkan informasi hue dan saturation sambil mempertahankan pencahayaan pada citra. Di bawah ini adalah gambar hasil konversi dari citra RGB ke Citra Grayscale.

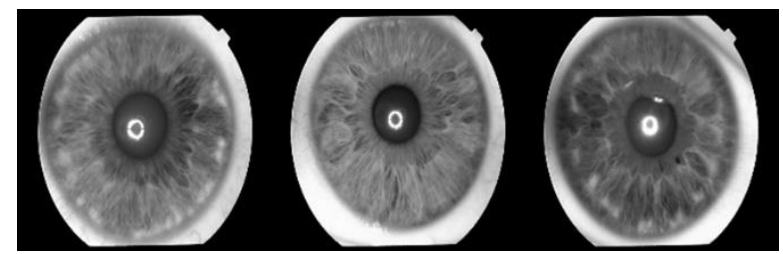

Sumber: (Herliana \& Arifin, 2019)

Gambar 3. Citra hasil konversi ke grayscale

\section{Contrast Limited Adaptive Histogram Equalization (CLAHE)}

Hasil dari grayscale mempunyai kontras yang rendah, sehingga menimbulkan kesulitan dalam mengenaili tekstur dalam iris mata, khususnya tekstur yang primitif atau sulit dikenali maka dalam penelitian ini digunakan tekni CLAHE untuk memperbaiki kontras hasil konversi dari grayscale, di bawah ini merupakan hasil dari perbaikan kualitas citra dengan menggunakan CLAHE.

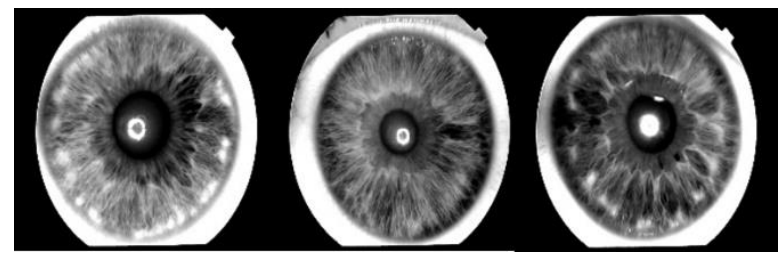

Sumber

Gambar 4. Perbaikan kuliatas citra dengan menggunakan CLAHE

3. Top Hat dan Bottom hat filtering

Teknik selanjutnya adalah menghapus pencahaan yang berlebih dan pencahayaan yang tidak merata pada citra dengan menggabungkan Teknik Top hat dan bottom hat, hal ini dilakukan karena hasil dari Teknik CLAHE pewarnaannya kurang merata. Di bawah ini adalah contoh gambar hasil Top Hat dan Bottom hat filtering.

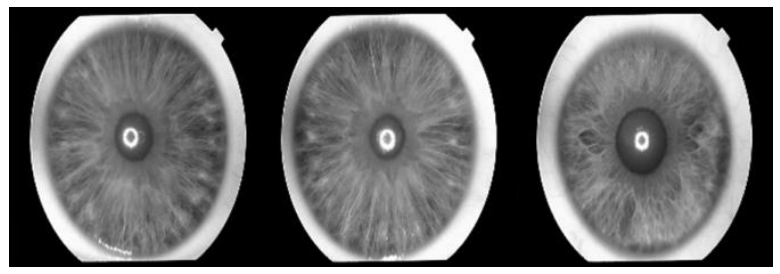

Sumber: (Herliana \& Arifin, 2019)

Gambar 5. Hasil dari Top Hat dan Bottom hat filtering

\section{Range Filtering}

Pada tahap Range Filtering, warna pada citra akan dirubah menjadi hitam dan putih yang bertujuan untuk menampilkan tekstur citra, termasuk tekstur yang primitif atau sulit dikenali, hal ini dilakukan agar memudahkan dalam penarikan informasi atau feature extraction. Di bawah ini adalah contoh gambar hasil dari konversi dengan teknik Range Filtering.

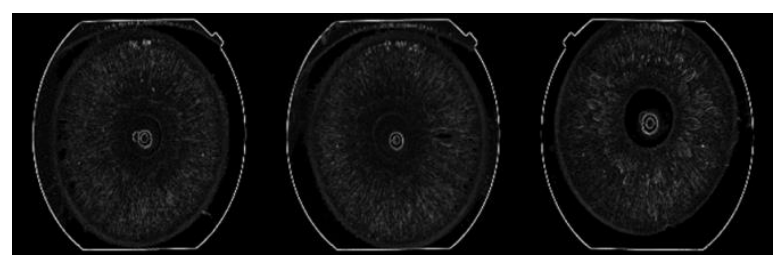

Sumber: (Herliana \& Arifin, 2019)

Gambar 6. Hasil konversi dengan teknik Range Filtering.

5. Analisa Tekstur GLCM

Tekstur merupakan karakteristik intrinsik dari suatu citra yang terkait dengan tingkat kekasaran 
(roughness), ukuran (granulation), dan keteraturan (regularity). Tekstur dapat didefinisikan sebagai fungsi dari variasi spasial intensitas piksel (nilai keabuan) dalam citra, metode GLCM termasuk dalam metode statistik dimana dalam perhitungan statistiknya menggunakan distribusi derajat keabuan, dan menggunakan 4 arah derajat keabuan yaitu 0 derajat, 45 derajat, 90 derajat dan 135 derajat (Arifin, 2015)(Arifin et al., 2014). Penelitian ini menggunakan algoritma Gray Level Co-occurrence Matrix (GLCM), untuk mengenali tekstur yang kecil dalam hal ini tekstur yang ada di citra iris mata. metode GLCM ini menghasilkan beberapa fitur dalam bentuk numerik yang akan digunakan dalam analisa tekstur. di bawah ini adalah beberapa fitur numerik beserta formulanya.

1. Contrast

$$
C(k, n)=\sum_{i} \sum_{j}(i-j)^{k} P_{d}[i, j]^{n}
$$

2. Correlation

$$
C_{c}=\frac{\sum_{i} \sum_{j}\left[i j P_{d}[i, j]\right]-\mu_{i} \mu_{j}}{\sigma_{i} \sigma_{j}}
$$

3.

$$
\text { Energy }
$$

$$
L_{e}=\sum_{i=1}^{m} \sum_{j=1}^{n}|C(i, j)|
$$

4. Homogeneity

$$
C_{h}=\sum_{i} \sum_{j} \frac{P_{d}[i, j]}{1+|i-j|}
$$

5. Entropy

$$
C_{e}=-\sum_{i} \sum_{j} P_{d}[i, j] \ln P_{d}[i, j]
$$

\section{HASIL DAN PEMBAHASAN}

Pada bab ini akan membahas hasil dari eksperimen yang sudah dilakukan, proses ini adalah proses akhir yang dilakukan setelah tahapan preprocessing, yaitu tahapan analisa tekstur dengan menggunakan algoritma GLCM (Gray Level Co-occurency Matrix), metode ini. digunakan dalam proses penarikan data atau feature extraction. Di bawah ini adalah table hasil atribut yang dihasilkan dari metode GLCM (Gray Level Co-occurency Matrix).

Tabel 1. Atribut GLCM (Gray Level Co-occurency Matrix)

\begin{tabular}{ll}
\hline No & Atribut \\
\hline 1 & Entropy \\
\hline 2 & Contrast 0 \\
\hline 3 & Contrast 45 \\
\hline 4 & Contrast 90 \\
\hline 5 & Contrast 135 \\
\hline 6 & Correlation 0 \\
\hline 7 & Correlation 45 \\
\hline 8 & Correlation 90 \\
\hline 9 & Correlation 135 \\
\hline 10 & Energy 0 \\
\hline 11 & Energy 45 \\
\hline 12 & Energy 90 \\
\hline 13 & Energy 135 \\
\hline 14 & Homogeneity 0 \\
\hline 15 & Homogeneity 45 \\
\hline 16 & Homogeneity 90 \\
\hline 17 & Homogeneity 135 \\
\hline 18 & Deviation \\
\hline 19 & Brightness \\
\hline
\end{tabular}

Sumber: (Herliana \& Arifin, 2019)

Di bawah ini adalah perbandingan data citra iris mata normal dan abnormal hasil dari tahapan ekstraski fitur

\section{Nilai Rata-rata Untuk Data Normal}

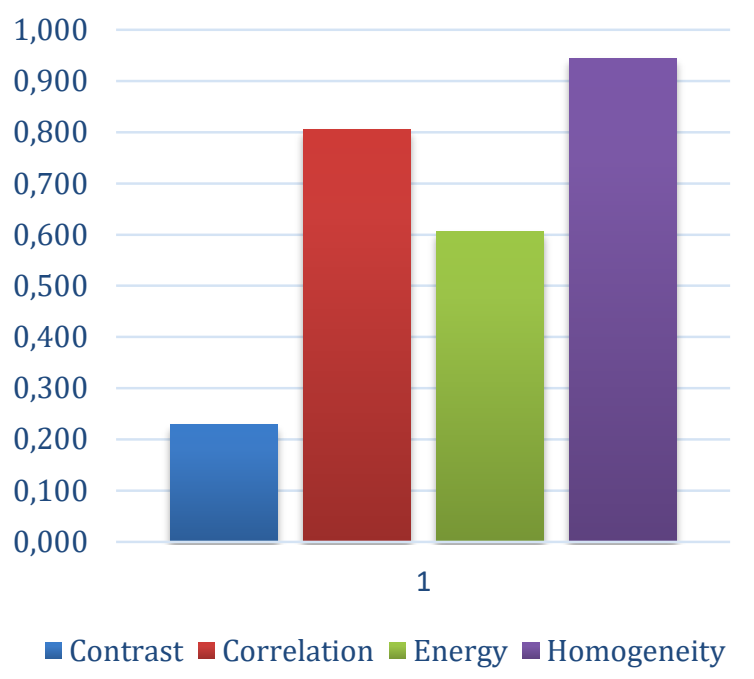

Sumber: (Herliana \& Arifin, 2019)

Gambar 7. Nilai Rata-Rata dari Hasil GLCM untuk Data Normal

Dari grafik di atas menunjukan nilai rata atribut correlation dan homogeneity lebih besar dari nilai yang lain, sedangkan nilai rata-rata, untuk nilai rata-rata atribut contrast beragam, 
grafik menunjukkan nilai rata-rata atribut contrast lebih kecil dari atribut yang lain. Di bawah ini adalah nilai atribut untuk data abnormal hasil dari metode GLCM.

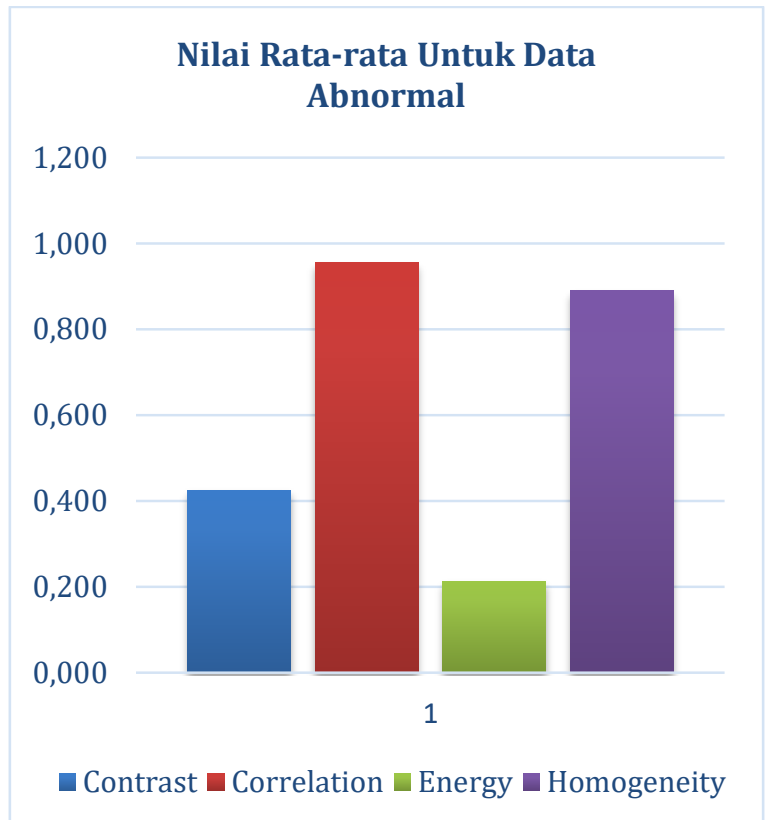

Sumber: (Herliana \& Arifin, 2019)

Gambar 8. Nilai Rata-Rata Hasil GLCM untuk Data Abnormal

Pada data di atas menunjukkan hasil data abnormal, nilai rata-rata paling tinggi adalah nilai atribut correlation sedangkan yang paling rendah ada diatribut Energy.

\section{KESIMPULAN}

Dari serangkaian eksperimen yang sudah dilakukan maka dapat ditarik kesimpulan sebagai berikut:

1. Tahapan preprocessing yang dilakukan dapat menghasilkan data yang cukup baik, dilihat dari hasil akhir dengan menggunakan teknik Range Filtering bentuk tekstur dapat terlihat jelas.

2. Proses feature extraction pada citra iris mata dengan menggunakan metode Analisa tekstur GLCM (Gray Level Co-occurency Matrix) dapat menghasilkan 18 atribut, dengan nilai yang beragam.

Untuk penelitian selanjutnya dapat dilanjutkan dengan pemberian kelas atau label untuk menentukan kriteria dari setiap data yang ada.

Analisa tektur juga dapat menggunakan metode lain yaitu Gray level different method (GLDM) atau Gray level run length method (GLRLM).

\section{REFERENSI}

Anantrasirichai, N., Achim, A., Morgan, J. E., Erchova, I., \& Nicholson, L. (2013). SVMbased texture classification in Optical Coherence Tomography. In 2013 IEEE 10th International Symposium on Biomedical Imaging (pp. 1332-1335). San Francisco: IEEE.

https://doi.org/10.1109/ISBI.2013.6556778

Annu, N., \& Justin, J. (2013). Automated classification of glaucoma images by wavelet energy features. International Journal of Engineering and Technology, 5(2), 17161721.

Arifin, T. (2015). Implementasi Metode K-Nearest Neighbor Untuk Klasifikasi Citra Sel Pap Smear Menggunakan Analisis Tekstur Nukleus. Jurnal Informatika, 2(1), 287-295. https://doi.org/10.31311/ji.v2i1.83

Arifin, T., \& Herliana, A. (2018). Optimasi Metode Klasifikasi dengan Menggunakan Particle Swarm Optimization untuk Identifikasi Penyakit Diabetes Retinopathy. Khazanah Informatika, 4(2), 77-81.

Arifin, T., Riana, D., \& Hapsari, G. I. (2014). Klasifikasi Statistikal Tekstur Sel Pap Smear Dengan Decesion Tree. Jurnal Informatika, 1(1). https://doi.org/10.31311/ji.v1i1.180

Biro Komunikasi dan Pelayanan Masyarakat. (2018). Indonesia Perlu Waspadai Gangguan Penglihatan. Retrieved from http://www.depkes.go.id/article/view/1811 0100003/indonesia-perlu-waspadaigangguan-penglihatan.html

Bron, J., C, C., \& A, B. (2006). Lecture Notes Oftalmologi (9th ed.). Jakarta: Erlangga Medical Series.

Dobe, M., \& Machala, L. (2012). Iris Data Base. Retrieved from http://phoenix.inf.upol.cz/iris/

Herliana, A., \& Arifin, T. (2019). Laporan Penelitian Akhir 2019. Bandung.

Herliana, A., Arifin, T., Susanti, S., \& Hikmah, A. B. (2018). Feature Selection of Diabetic Retinopathy Disease Using Particle Swarm Optimization and Neural Network. 2018 6th International Conference on Cyber and IT Service Management (CITSM), (Citsm), 1-4. 
https://doi.org/10.1109/CITSM.2018.86742

95

Mesecan, I., Eleyan, A., \& Karlik, B. (2013). Siftbased iris recognition using sub-segments. 2013 The International Conference on Technological Advances in Electrical, Electronics and Computer Engineering, TAEECE 2013, 350-353. https://doi.org/10.1109/TAEECE.2013.6557 299

Pusat Komunikasi Publik Sekretariat Jenderal Kementerian Kesehatan RI. (2010). Gangguan penglihatan masih menjadi masalah kesehatan. Retrieved from http://www.depkes.go.id/pdf.php?id=845

Situmorang, G. T., Widodo, A. W., \& Rahman, M. A. (2019). Penerapan Metode Gray Level Cooccurence Matrix ( GLCM ) untuk Ekstraksi Ciri pada Telapak Tangan. Jurnal Pengembangan Teknlogi Informasi Dan Ilmu Komputer (J-PTIIK) Universitas Brawijaya, 3(5), 4710-4716. Retrieved from http://jptiik.ub.ac.id/index.php/jptiik/article/view/5322

Widodo, R., Widodo, A. W., \& Supriyanto, A. (2018). Pemanfaatan Ciri Gray Level Co-Occurrence Matrix ( GLCM ) Citra Buah Jeruk Keprok ( Citrus reticulata Blanco ) untuk Klasifikasi Mutu. Jurnal Pengembangan Teknlogi Informasi Dan Ilmu Komputer (J-PTIIK) Universitas Brawijaya, 2(11), 5769-5776. Retrieved from http://jptiik.ub.ac.id/index.php/j-

ptiik/article/view/3420 